\title{
RADIOLOGIA CONTRASTADA DO TIMO NA MIASTENIA GRAVE
}

\author{
José Lamartine de AsSis * \\ IBANEZ DE CARVALHo **
}

\begin{abstract}
Ainda que seja admitida estreita correlação entre timo e miastenia grave, nem sempre tem sido possível documentar a persistência ou hiperplasia do timo nos pacientes miastênicos. Na grande maioria dos casos que tivemos oportunidade de estudar, as radiografias simples bem como as tomografias do mediastino anterior e superior não permitiram visualizar e nem mesmo suspeitar da existência de timo, persistente ou hipertrófico. Isto nos levou a uma pesquisa semiológica mais acurada mediante o uso do enfisema do mediastino com documentação radiológica (pneumomediastinografia e/ou pneumoplanigrafia).

As primeiras tentativas de visualização mais acurada do timo foram feitas à custa de contrastes líquidos radiopacos à base de iôdo, substâncias que, sendo irritantes, provocam reaçōes inflamatórias com fibrose ulterior. Condorelli, citado por Sarteschi e Berttolo 5, utilizou, em 1936, o contraste gasoso, introduzindo-o ao nível da fúrcula esternal. Desde então êste método tem sido utilizado por vários autores $2,3,4,5$, mas não tem tido a divulgação que merece, pois ainda continuam a aparecer trabalhos em que êste método nem sequer é citado. Em nossa opinião o valor do pneumomediastinograma na miastenia grave é de tal ordem que o método deve entrar na rotina de exames em casos daquela doença.
\end{abstract}

\section{MATERIAL E METODOS}

No material, compreendendo 20 pacientes com idades variáveis entre 6 e 62 anos, todos com miastenia grave, nāo foram ineluídos casos com timoma. Os exames radiológícos simples do tórax, com exposiçāo do mediastino anterior e superior, nas incỉências clássicas não mostraram a presença de imagem timica; apenas em dois casos (casos 12 e 17) foi visto alargamento do mediastino anterior e superior, não permitindo conclusão definttiva. Em alguns dêstes pacientes a planigrafia havia sido também negativa quanto à visualização do timo. Nos casos 3, 4, 5, 6, 7 e 12, além de radiografias simples, foram feitas planigrafias e, depois, radiografias contrastadas. Nos casos 1, 2, 3, 4, 6, 7, 8, 9, 10,11, 13, 14, 15, 17 e 20, além dos exames radiológicos não contrastados e do pneumomediastínograma, foram feitas, também, pneumoplanimediastinografias. Nestes casos foi possivel estudo comparativo entre êsses diferentes métodos propedeuticos.

Trabalho da Faculdade de Medicina da Universidade de São Paulo, apresentado à I Reunião Anual da Academia Brasileira de Neurologia, realizada de 30 de junho a 5 de julho de 1963 em Curitiba: * Docente-livre de Clínica Neurológica (Prof. Adherbal Tolosa); ** Docente-livre de Clinica Cirúrgica. 
Técnica do pneumomediastino* Nos casos aqui registrados não foi feito preparo prévio algum, como jejum, sedação ou uso de droga parassimpaticomimética; entretanto, nos casos muito graves, especialmente com grande comprometimento respiratório, poderá ser usada a injeção subcutânea de $0,025 \mathrm{mg}$ de sulfato de atropina e major dose de anticolinesterásico, uma hora antes. Dos 20 pacientes estudados, apenas um necessitou de prostigmina ao término do exame por estar com dificuldade respiratória maior.

O paciente é pósto em decủbito supino com almofada sob as espáduas, com a finalidade de permitir discreta extensão do pescoço. Anestesia local com novocaina a $1 \%$ sem adrenalina, fazendo-se botāo dérmico a 2 ou $3 \mathrm{~cm}$ acima da linha média da fủrcula esternal, ou seja, a iguă distância de ambos os cabos de inserçāo esternal dos músculos esternocleidomastóideos. Introdução perpendicular da aguiha numa profundidade de 2 a $3 \mathrm{~cm}$, tendo-se o cuidado de ir inclinando a ponta em direcão ao esterno, de maneira a penetrar rasante ao osso para evitar lesão dos grandes vasos da base. Dêste modo serão atravessados os seguintes planos: pele, tecido celular subcutāneo, aponeurose cervical superficial, músculos pré-tireóideos, aponeurose cervical média e tecido frouxo do mediastino anterior superior. A agulha de punção quando em boa posição costuma ficar oscilando, no que acompanha as pulsaçōes cardiacas. Introduzir 1 a $2 \mathrm{ml}$ de anestésico para aliviar a sensaçāo da presença a êste nivel da agulha.

o gás utilizado foi o ar, por ser mais simples a sua obtenção e porque é bem tolerado, mesmo permanecendo durante 24 horas no mediastino. A quantidade de ar injetada variou de 200 a $400 \mathrm{ml}$ para os adultos e 100 a $200 \mathrm{ml}$ para as crianças. Nas crianças menores ou distróficas podem ser injetados apenas 50 ou $100 \mathrm{ml}$ de ar. A injeçāo deve ser lenta, para evitar desconfôrto e sensaçāo de opressâo retrosternal, aspirando para evitar a punçāo de vaso. As condições ideais de contrastação sāo atingidas quando aparece timpanismo em tôda a área esternal. $O$ paciente movimenta-se e, assim que puder, deve assumir o ortostatismo para que o ar se difunda melhor pelo mediastino, particularmente no mediastino anterjor e superior. Após a injeção e difusāo do ar sāo tiradas chapas em ântero-posterior, perfil e obliqua. Este exame pode ser complementado com planigrafia do mediastino anterior e superior; nos casos em que isto aconteceu foram praticados em média três cortes tomográficos.

Depois da feitura do pneumomediastino, de regra, os pacientes se queixavam apenas de sensação de desconfôrto ou de constrição retrosternal e dor. Em geral êstes sintomas são discretos e passageiros. Em alguns casos esta sintomatologia se prolongou por alguns dias. Excepcionalmente, nas primeiras horas, houve queixa de leve dispnéia. Nenhum paciente acusou complicaçōes graves. Jamais tivemos acidente de punção. Aliás o único acidente possivel seria penetraçāo exagerada da agulha em direção imprópria com lesāo da tireóide ou de vasos da base.

\section{PESULTADOS}

Os resultados expressos neste trabalho foram calcados sôbre 20 casos de pacientes portadores de miastenia grave com persistencia ou hipertrofia do timo. A imagem do timo persistente ou hipertrófico aparece entre a silhueta cardiovascular e o esterno (fíg. 1). Esta imagem é visivel no mediastino anterior e superior, evidenciada em àntero-posterior como parênteses se destacando de cada lado da sombra densa, central, dos vasos da base (fig. 2).

Nesta posição, se o lobo esquerdo do timo fôr mais volumoso, pode simular cardiopatia mitral dada a acentuação do arco médio; entretanto, essa imagem é

* Agradecemos ao Dr. Radyr de Queiroz o valioso auxilio prestado na interpretaçăo das chapas radiológicas e à Sra. Irma Bonadio pelo trabalho técnico na feitura das radiografias. 
dissociada da silhueta cardiovascular quando do enfisema do mediastino, pelo ar, o que permite diagnóstico exato. Na radiografia nāo contrastada e em ânteroposterjor é mais corrente a sua não aparição, quer à direita como à esquerda. Excepcionalmente o exame radiológlco simples em incidencia frontal evidencia o alargamento do mediastino anterior e superior no caso de persistência do timo (casos 12 e 17); todavia, apenas no caso 12 o pneumomediastino pôde comprová-10. No perfil a radiografia contrastada mostra o timo como imagem única, dupla ou tripla, alongada, ou triangular com o ápice afilado para baixo, ou para cima, em virgula, em escaravelho e em cunha (figs. $3,4,5,6,7$ e 8 ).
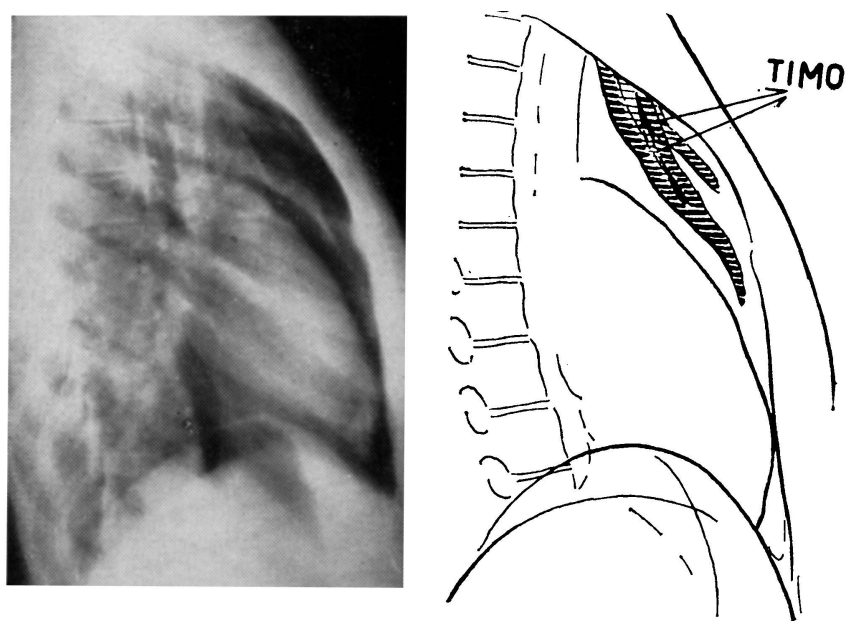

Fig. 1 - Caso 5 (D.R.). Pneumomediastino: em perfil esquerdo, imagem tímica como lingüeta interposta entre o esterno $e$ os vasos da base no mediastino anterior $e$ superior.
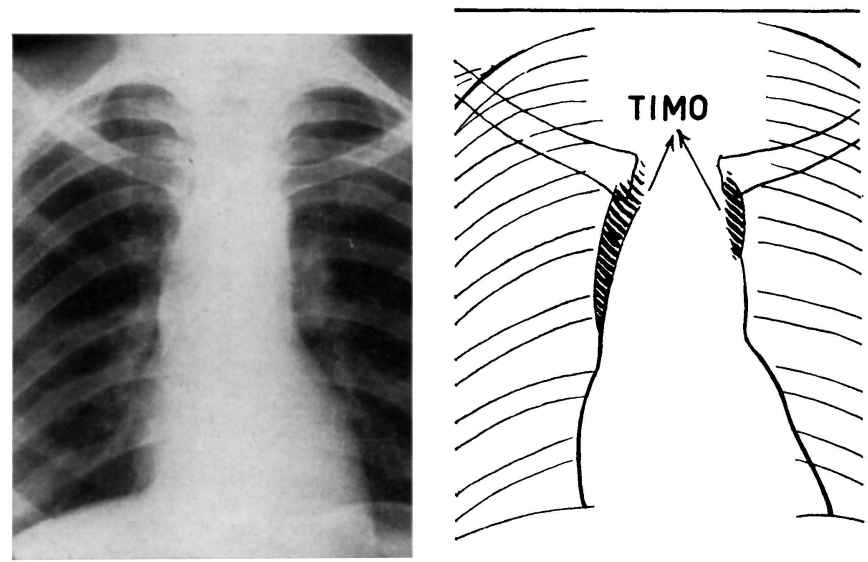

Fig. 2 - Caso 2 (A.N.G.). Pneumomediastino: alargamento do mediastino superior, destacando-se imagem linear em parênteses abaixo das claviculas. 
A pneumomediastinografia em perfil mostrou-se ser a incidência mais apropriada para a documentação da existência do timo persistente, dado o contraste estabelecido entre as várias estruturas mediastinais. E de notar que a radiografia simples náo demonstrou, de modo seguro, imagem de timo em qualquer dos nossos pacientes. Nos casos 12 e 17 havia alargamento do mediastino anterior e superior no exame radiológico simples em incidēncia frontal, mas que não permitiu o diagnóstico de hipertrofia ou persistência do timo. Nestes dois casos a incidencia de perfil nada visualizou de anormal.
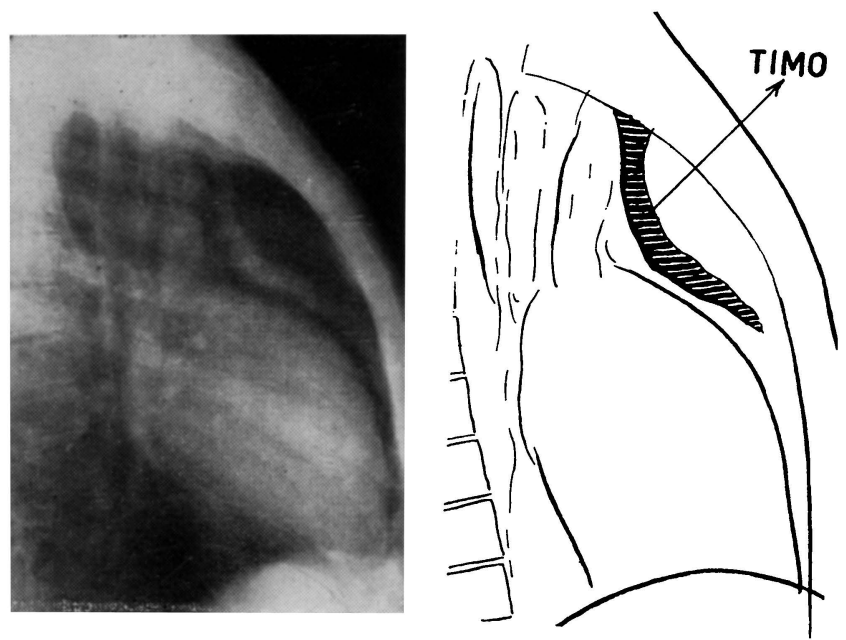

Fig. 3 - Caso 10 (H.T.B.). Pneumomediastino: imagem tímica, laminar e única, no mediastino ântero-superior lvide pneumoplanigrafia dêste caso na fig. 6).
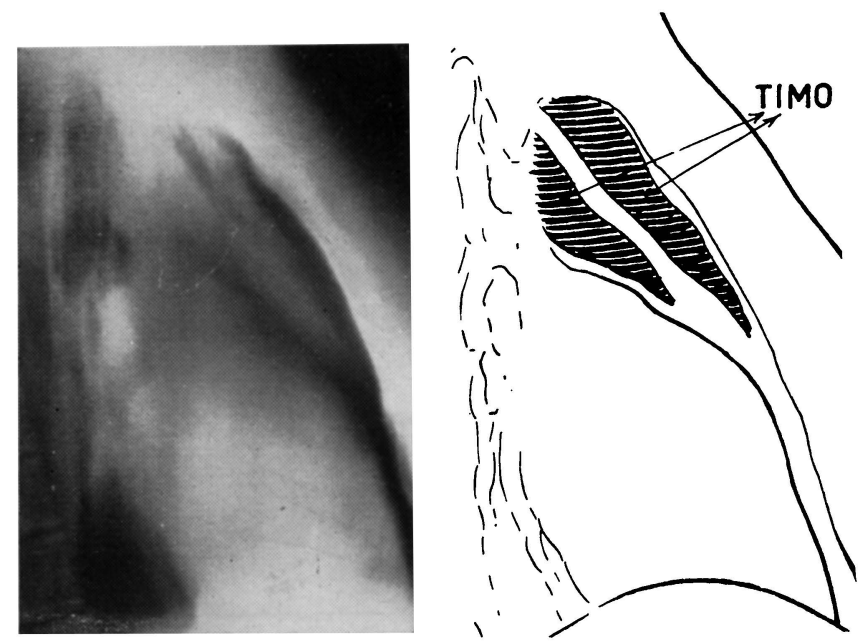

Fig. 4 - Caso 8 (A.P.), Pneumoplanimediastinografia: timo com dois lobos alongados. 
A pneumoplanimediastinografia permitiu estudar com mais nitidez o aspecto, dimensões, topografia e saber quais os cortes tomográfjcos onde mais freqüentemente se evidencia a imagem tímica. Os lobos são de dimensões variadas (figs. $1,4,5$ e 7), estabelecendo flagrante contraste com as outras estruturas do mediastino anterior e superior.

Os cortes tomográficos que melhor exibiram o timo foram: T.E. 2, que por 11 vêzes demonstrou o timo; em T.E.O., em que êle foi visto 4 vêzes; em T.D. 1 três vêzes e, finalmente, em T.E., uma vez apenas. Portanto, o corte planigráfíco que
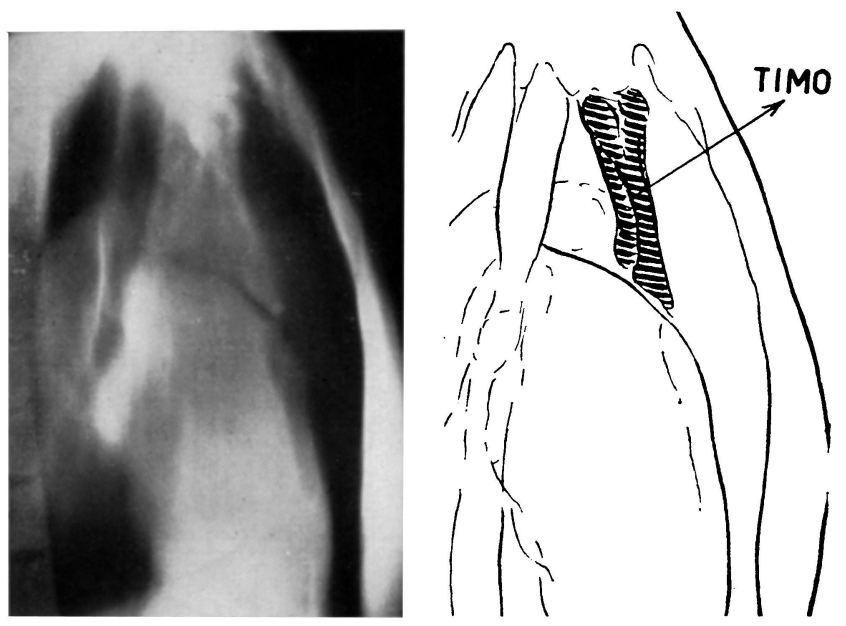

Fig. 5 - Caso 13 (M.C.G.). Pneumoplanimediastinografia: imagem timica alongada desde o nivel da fúrcula até a altura da base do coração.
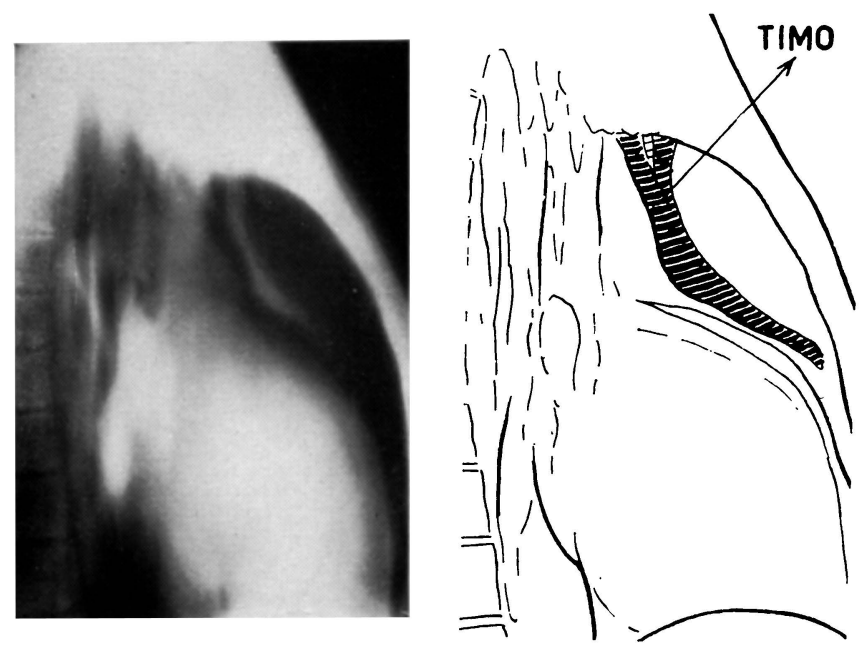

Fig. 6 - Caso 10 (H.T.B.). Pneumoplanimediastinografia: imagem tímica alongada $e$ de ápice afilado dirigido para baixo. 
mais exibe a imagem de timo persistente ou hipertrófico é o corte distante $2 \mathrm{~cm}$ da linha mediana à esquerda (fig. 9).

As vêzes a imagem timica se prolonga em sentido caudal, entre o esterno e o coraçáo (caso 5, fig. 1), fato êste de importância para o radioterapeuta e para o cirurgião.

Em todos os casos, com exceção dos casos 6 e 17, foi observada imagem timica com radiografia contrastada; no cașo 6 , as condiçōes técnicas não foram ideais.
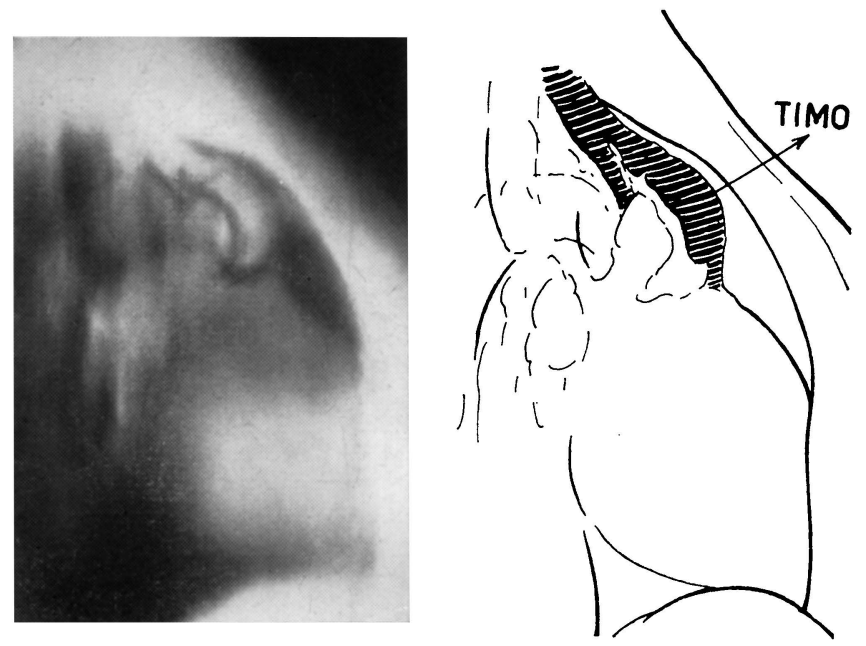

Fig. 7 - Caso 4 (I.D.). Pneumoplanimediastinografia: imagem tímica dupla, em vírgula.
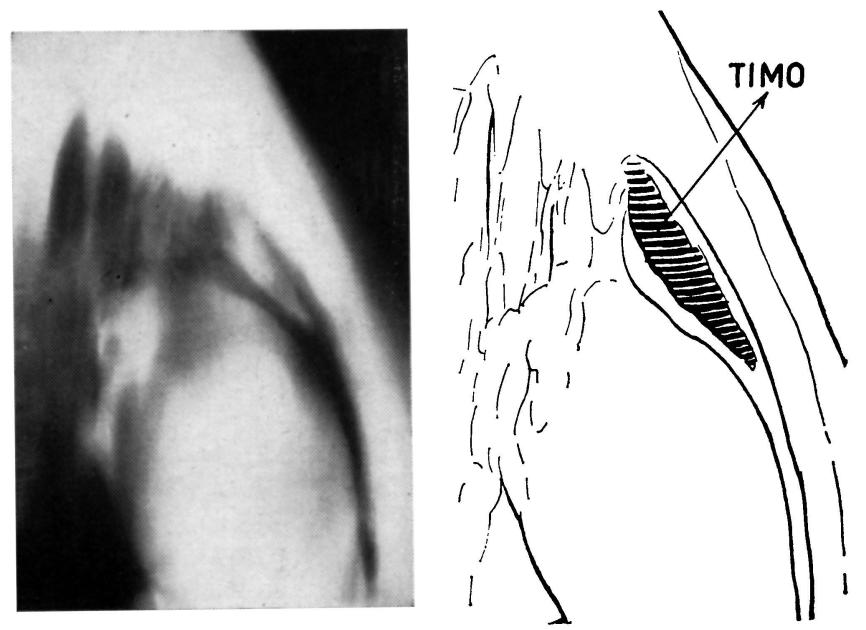

Fig. 8 - Caso 9 (C.C.). O corte tomográfico do mediastino ântero-posterior com enfisema provocado mostra imagem timirt. em cunha. 
A involuçāo do órgāo foi verificáda em um caso submetido ao tratamento pelo ACTH (caso 13) e um outro tratajo pela radioterapia (caso 20). Em dois pacientes submetidos à timectomia (casos 18 e 19) foi possivel o contrôle radiológico pré e pós-operatório. Entretanto, o número de casos é pequeno para permitir conclusōes dos achados radiológicos do timo, após tratamento pelo ACTH, radioterapia $\epsilon /$ ou timectomia.
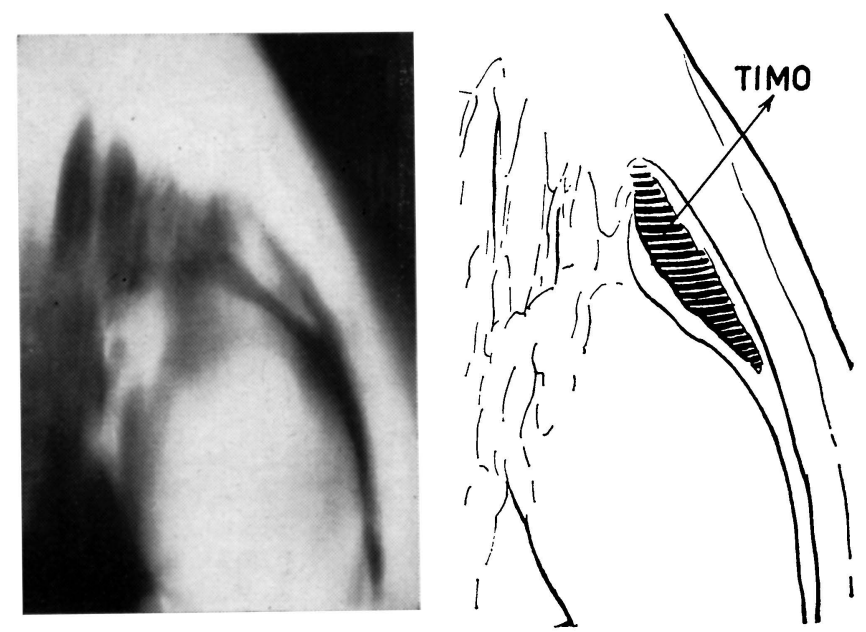

Fig. 9 - Caso \& (A.N.G.). Corte tomográfico na vigência de enfisema do mediastino permitindo contrastar as imagens sediadas no mediastino anterior e superior: vasos da base, arco ártico, base do coracāo e timo.

Todos os pacientes estavam sob tratamento, variável conforme a evoluçāo da dcença: em trēs casos foi feita radioterapia profunda do timo, em três outros a timectomia; em 8 casos foi empregado o ACTH pela via intravenosa. Todos os pacientes faziam uso de drogas anłicolinesterásicas, mesmo durante e após os tratamentos radioterápicos, cirúrgicos ou pelo $\mathrm{ACTH}$.

\section{COMENTÁRIOS}

O enfisema do mediastino é método semiológico de fácil execução e inócuo, devendo fazer parte da rotina propedêtica em todos os casos de miastenia grave. Trata-se do melhor meio semiológico para estudo do mediastino anterior, pois, dada a grande contrastação que estabelece, permite fazer o diagnóstico de persistência ou hipertrofia do timo e a diferenciação com tumores benignos ou malignos do órgão, assim como com outros proCesscs sediados no mediastino.

Com êste método poder-se-á acompanhar a evoluçāo em face de determinadas terapêuticas, como é o caso da irradiação do timo ou o emprêgo do ACTH. Além disso, nos casos em que vai ser feito tratamento cirúrgico, o método poderá orientar o cirurgiāo, pelo reparo radiológico prévio quanto às condiçōes locais e possivveis dificuldades a serem encontradas. 


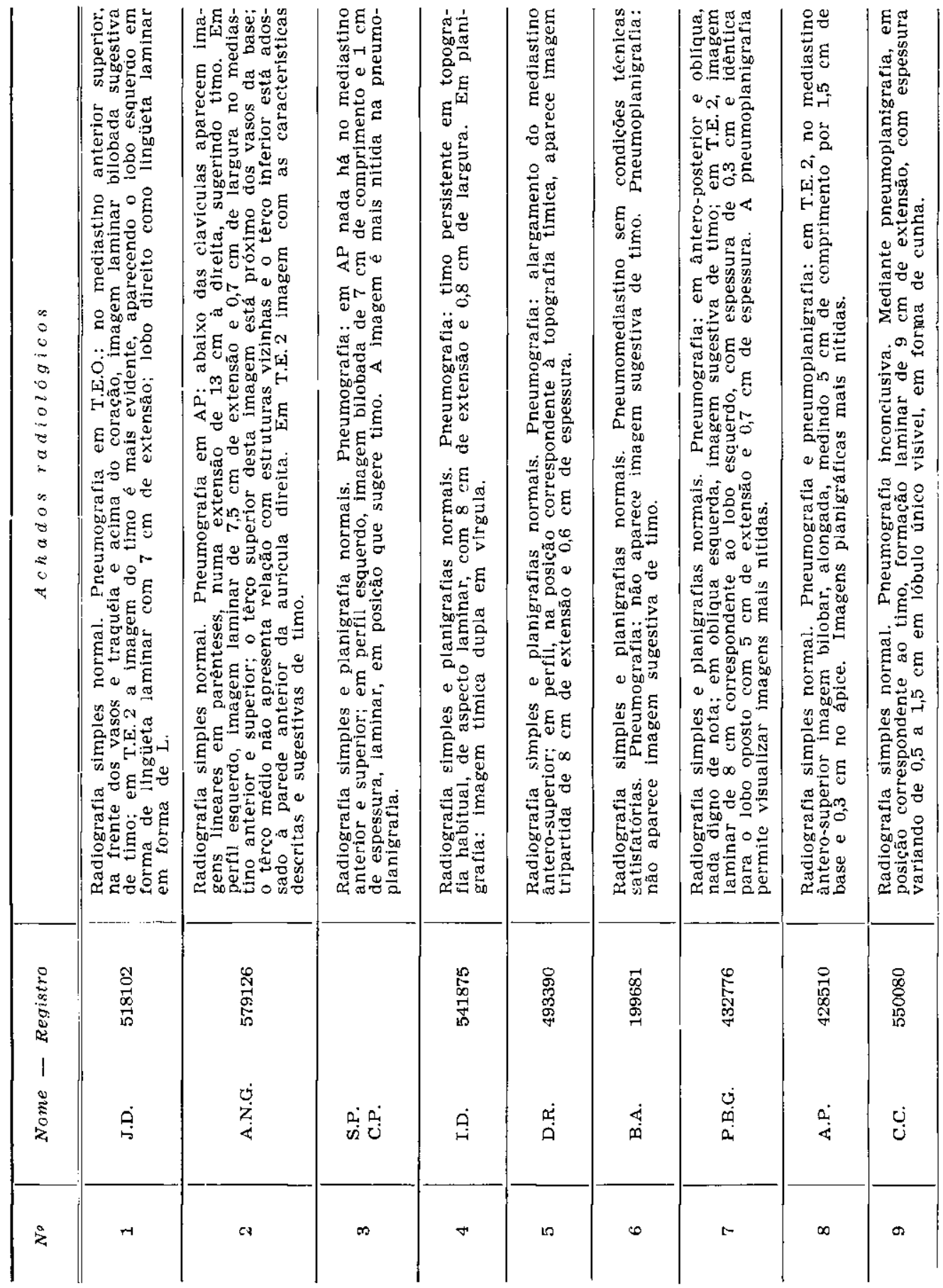




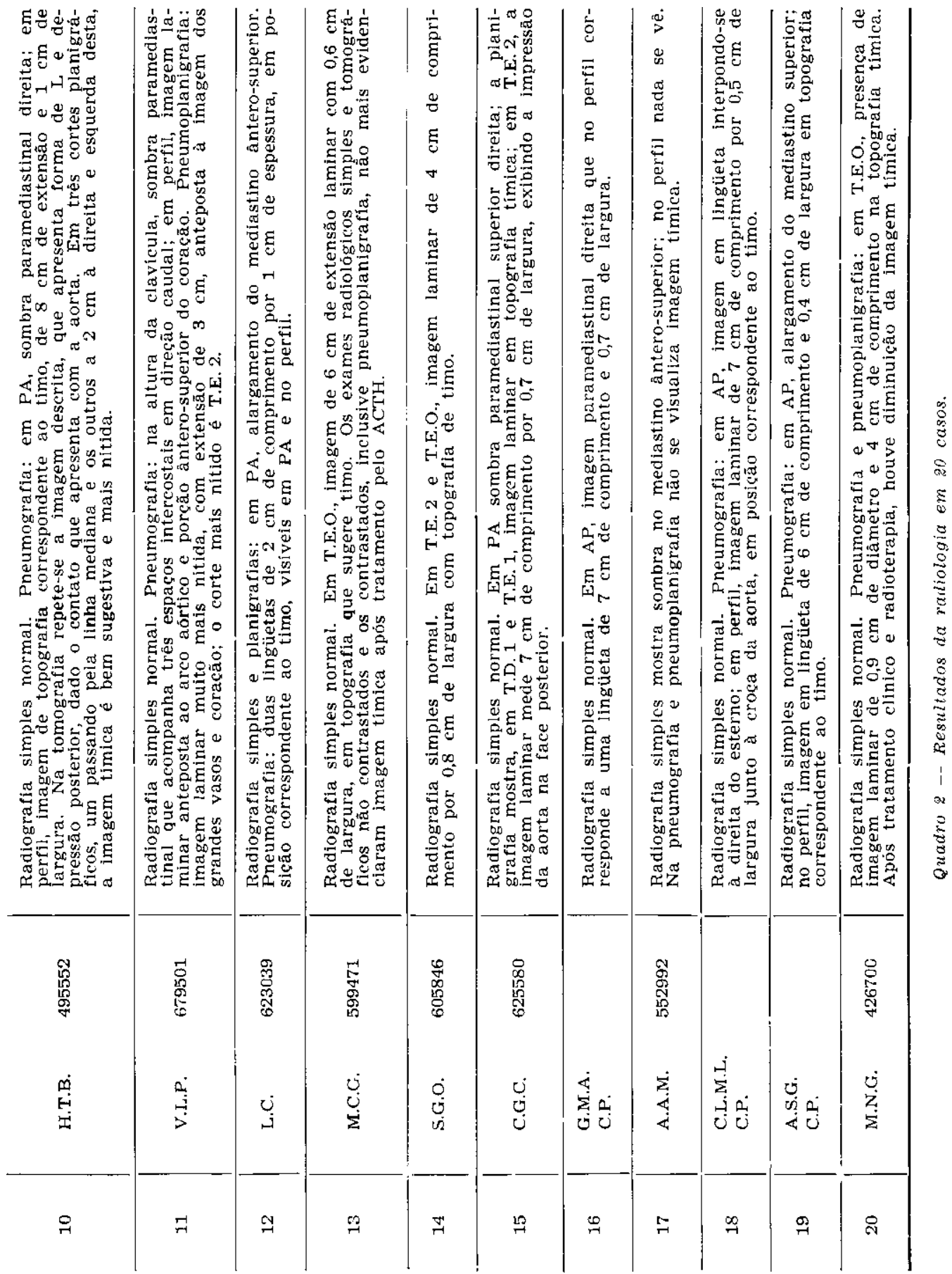


Nasce assim o planejamento técnico e tático para a abordagem do órgão. Isto permite, às vêzes, a feitura de timectomia por via cervical cuja inocuidade não se faz necessário enaltecer.

O estudo comparativo entre os exames radiológicos simples e os contrastados mostrou que os primeiros, mesmo quando utilizada a técnica planigráfica, são insuficientes para caracterizar a persistência de timo, enquanto os segundos permitem demonstrar, de modo satisfatório na maioria dos casos, a existéncia de imagem tímica. O enfisema contrastando e dissociando as estruturas do mediastino, visualiza o timo, dá sua forma, número de lóbulos, posição e extensảo de modo preciso, o que tem grande valor prático quando se pretende irradiar ou extirpar o órgāo.

A pneumoplanimediastinografia, feita na maioria de nossos pacientes, permitiu obter imagens timicas mais nitidas além de caracterizar a persis. tência do timo em quase todos os casos.

Do nosso material submetido ao exame radiológico contrastado do timo, sỏmente em dois casos não se evidenciou a imagem do órgão (casos 6 e 17); no caso 6 o enfisema do mediastino não foi obtido em condiçōes técnicas satisfatórias.

\section{CONCLUSOES}

O estudo radiológico simples e com enfisema do mediastino em 20 pacientes com miastenia grave, embora não permita conclusōes definitivas, justifica as seguintes conclusões de interêsse prático: o enfisema do mediastino é método fácil e inócuo, devendo entrar na rotina terapêutica de todos os casos de miastenia grave; o exame radiológico não contrastado, em nosso material, não demonstrou imagem timica de modo conclusivo; o pneumomediastinograma, feito dentro de condiçōes técnicas satisfatórias, revelou imagem tímica em 18 casos; a planigrafia com pneumomediastino (pneumoplanimediastinografia) é o método mais eficiente, por permitir visualizar o timo de modo mais nítido e completo.

\section{RESUMO}

Foram estudados 20 casos de miastenia grave mediante exame radiológico simples para evidenciar a persistência ou hipertrofia do timo e estudar, comparativamente, os resultados dêste método propedêutico com o uso do enfisema do mediastino seguido de pneumografia e/ou planigrafia. Com tal procedimento foi possivel mostrar, em 18 dos casos, a persistência ou hipertrofia do timo. Em alguns casos foram analisados os diversos aspectos radiológicos do timo em suas relações com as medidas terapêuticas, adotadas em particular com o uso do $\mathrm{ACTH}$, radioterapia e/ou timectomia; neste particular, os autores nāo puderam tirar conclusōes definitivas por ser pequeno o número de casos estudados. 


\section{SUMMARY}

Contrasted radiology of the thymus in myasthenia gravis.

The authors studied 20 cases of myasthenia gravis with radiological examination showing the persistence or hipertrophy of the thymus. In these cases were made radiological examination without contrast and with mediastinal emphysem. The persistent of hypertrophy thymus is proved by this last method in almos all cases.

The several radiological aspects of the thymus were analysed and its relations with the therapeutic by $\mathrm{ACTH}$, radiotherapy and/or thymectomy presented; however, in this field, the authors can't be conclusive because they have still a few cases.

\section{REFERENCIAS}

1. AlajouAnine, Th.; BARIETy, M.; CASTAIGNE, P. \& COURY, Ch. - Sur l'utilité de la médiastinographie gazeuse pour la mise en évidence des tumeurs thymiques chez les myasthéniques. Rev. Neurol., 96:3, 1957. 2. BARIETY, M.; COURY, Ch. \& GIMBERT, J. L. - Anomalies thymiques, myasthenie grave et médiastinographie gazeuse. Sem. Hôp. Parłs 66:3445, 1956. 3. BODEY, G. P. - Medical mediastinal emphysema. Ann. Int. Med., 54:46, 1961. 4. COURY, C. - Les tumeurs du thymus. Presse Méd., 69:1551, 1961. 5. SARTESCHI, G. \& BERTTOLO, G. R. - Il timo. Studio fisiopatologtco clinico e terapeutico delle affezioni chlrurgiche dell'organo. Edizioni Omnia Medica, Pisa, 1957.

Clínica Neurológica - Faculdade de Medicina da Universidade de São Paulo Caixa Postal 3461 - Sảo Paulo, Brasil. 